\title{
SPATIO-TEMPORAL STUDY OF BRAHMAPUTRA RIVER ISLANDS (CHARS) FOR AGRICULTURE EXPANSION IN ASSAM, INDIA
}

\author{
Meghavi Prashnani ${ }^{1 *}$, Abdul Qadir ${ }^{2 *}$, J.Goswami ${ }^{3}$, P.L.N Raju ${ }^{3}$ \\ ${ }^{1}$ University of Maryland, College Park, USA \\ ${ }^{2}$ University of Delaware, Newark, USA \\ ${ }^{3}$ North Eastern Space Application Centre, Dept. of Space, Meghalaya, India \\ meghavi@umd.edu, abdulqa@udel.edu,jonali.goswami@nesac.gov.in,director@nesac.gov.in \\ * equal authorship
}

Commission III, WG III/10

KEY WORDS: Agriculture expansion, River Island, Google Earth Engine, Landsat, River dynamics.

\begin{abstract}
:
The present paper aims to understand the spatio-temporal dynamics of the Brahmaputra river islands locally known as chars in Assam for agriculture crop expansion using long term multispectral satellite data and Google Earth Engine. This study also provides information on existing agriculture lands on these chars. For the study Landsat data is analysed to find the long term stable islands (1988-2018) and the present status of these islands for seasonal crop expansion. Validation of results was performed by using highresolution satellite data. It is found that total area of vegetative chars has increased in past three decades and approximately 146 thousand hectares area of char is stable from past ten years. This study also reveals that the major crop cultivation is in Lower Brahmaputra Valley (LBV). In Upper Brahmaputra Valley (UBV), the crop cultivation is almost negligible compared to the large islands size. It can be inferred that less stable chars which are mostly located in upper Assam has negligible agriculture. It is also observed that at many places in lower Assam, double cropping system is followed. This study can be further extended by including factors like soil type, soil texture, rainfall, socio-economic etc. to study suitability for different crops. Proper facilities and incentives are to be provided to farmers of this region for better food security.
\end{abstract}

\section{INTRODUCTION}

In Assam, agriculture is the most dominant sector contributing significantly to the economy of the state and providing employment to lakhs of people (De et al. 2014, Gogoi et al, 2011). Due to limited agriculture land, low yield, small farm holding the crop productivity in the region is less compared to the national average. With changing climatic conditions and volatility in markets, the food production also remains uncertain (NITI Aayog report 2015). This demands the government to take constructive measures for increasing the food production in the region. For increasing the food production not only the cropping intensity in the existing cropland has to increased but also the area under food production has to be expanded and new suitable areas in the state has to identified (Gogoi et al, 2011). Every year due to migration of the Brahmaputra river, erosion of thousands of hectares of land including the agriculture land is continuously occurring both sides of the river thus leading to more shortage of land (Sarkar et al. 2012, Thakuriah et al. 2018). Due to limited land in the mainland Assam, the alternative area for crop expansion has to be explored. For this, the Brahmaputra river islands locally known as chars provide alternatives for crop expansion in the non-flooding seasons. But the dynamics of these islands has to be understood properly for better utilization of them for agriculture purposes.

In Assam, Brahmaputra river extends over $650 \mathrm{~km}$ covering thousand hectares from upstream at Dibrugarh to the Dhubri town in lower Assam near Bangladesh border (Lahiri et al 2012, NESAC Report 2003). The Brahmaputra is characterised by its highly braided channel pattern which has given rise to number of river islands(chars) of various sizes and shapes (Best el al. 2007, Sarkar et al. 2012). With yearly occurring floods these islands keep on changing in shape, sizes and orientation (LahiriDutta 2014, Hazarika et al. 2015). Many of such chars remain stable for long period of time allowing vegetation to grow up and settlement to establish (Rahman et al. 2012).

These islands, which are stable for long duration (a decade or more), may be utilized for growing horticulture and plantation crops, while islands, which are relatively less stable (less than a decade) may be used for growing short duration seasonal crops such as vegetables. But majority of these chars remains fallow and unutilized for the entire duration. These chars have the potential for agriculture expansion as the soil is fertile and productive (Best et. al, 2007). Keeping in view the changes in the river configuration of the Brahmaputra main channel this study has been undertaken using the google earth engine platform with the following objectives.

1) To identify the stability of the river Island/vegetative islands (char) over the thirty years period from 1988 to 2018 using multi-spectral satellite data.

2) To identify and map the present status of the chars for the year 2017-18 and understand the status of the agriculture pattern in these chars.

\section{STUDY AREA}

The study area consists of the Brahmaputra river boundary in Assam state of India. The river has its origin in the Himalayas and flows through China, India and Bangladesh. Its extensive river system drains unique physical settings of diverse environments such as the cold, dry plateau in Tibet, the steep rain drenched slopes of Himalayas, the landlocked alluvial plains of Assam and the vast dialectic plain in Bangladesh. The river traverses the total distance of $2906 \mathrm{~km}$ through the Tibetan plateau, The Himalayan mountains and hills and plains until reaching the Bay of Bengal. The Brahmaputra basin covers the area of 580 thousand sq. km of which 195 thousand sq. km falls 
within India. In Assam, Brahmaputra River flows through a distance of approximately $650 \mathrm{~km}$. The location of Brahmaputra river in Assam is shown in the Figure 1.

For mapping and quantification of the chars having agriculture, the entire Brahmaputra stretch is divided into three regions,

1. Lower Brahmaputra Valley (LBV) - From Bangladesh Border in Dhubri to Saraighat Bridge in Guwahati.

2. Central Brahmaputra Valley (CBV) - From Saraighat to Kolia Bhomora Bridge near Tezpur and

3. Upper Brahmaputra Valley (UBV) - From Kolia Bhomora bridge to Tinsukia bordering Arunachal.

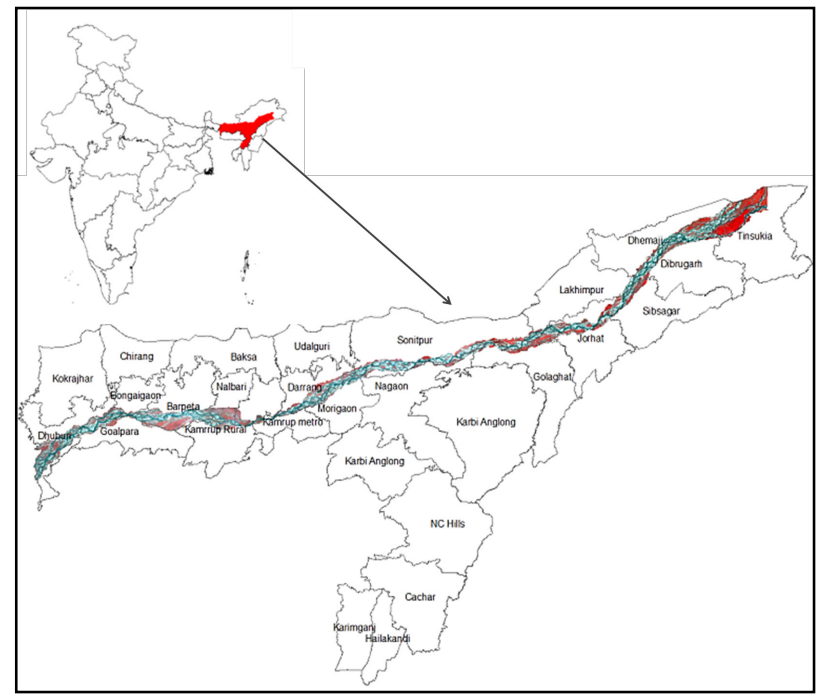

Figure 1. Brahmaputra River in Assam, India

\section{DATA USED}

For this study, geometrically corrected Landsat satellite images converted from radiance to reflectance were fetched from United States Geological Survey (USGS) server using Google Earth Engine (GEE) (Gorelick et al. 2017). Satellite data for the months from November to April for the years 1987-1988, 1997 $1998,2007-2008$ and 2017-2018 is used. Monthly, cloud free scenes from November to April is taken, median reflectance values of these scenes are combined to prepare a single cloud free composite image for the entire stretch of Brahmaputra as shown in the figure 1 above. For identifying the present status of the islands Sentinel-2 imagery for the non-monsoon season (November-April) is used. For validation of the results, high resolution Planet lab satellite data is used. The river extent was taken according to the river extent boundary for that particular year calculated during the non-monsoon season.

\section{METHODOLOGY}

The stable river islands or chars remain stable for long period of time allowing vegetation to grow thus turning into vegetative islands. These vegetative chars were mapped using the Normalised Difference Vegetation Index (NDVI) values over the entire Brahmaputra stretch, using the Landsat Cloud free composite images. A decision rule based algorithm is used for mapping and separating these chars from the existing sandbars and the river water. The NDVI values of the chars which remain stable for long duration shows signs of vegetation thus gives higher NDVI compared to sandbars or water. The spectral reflectance and NDVI values of chars having agriculture land also keeps on changing for the entire crop cultivation season from sowing to harvesting. All the data sets within Brahmaputra boundary layer were analysed in the Google Earth Engine

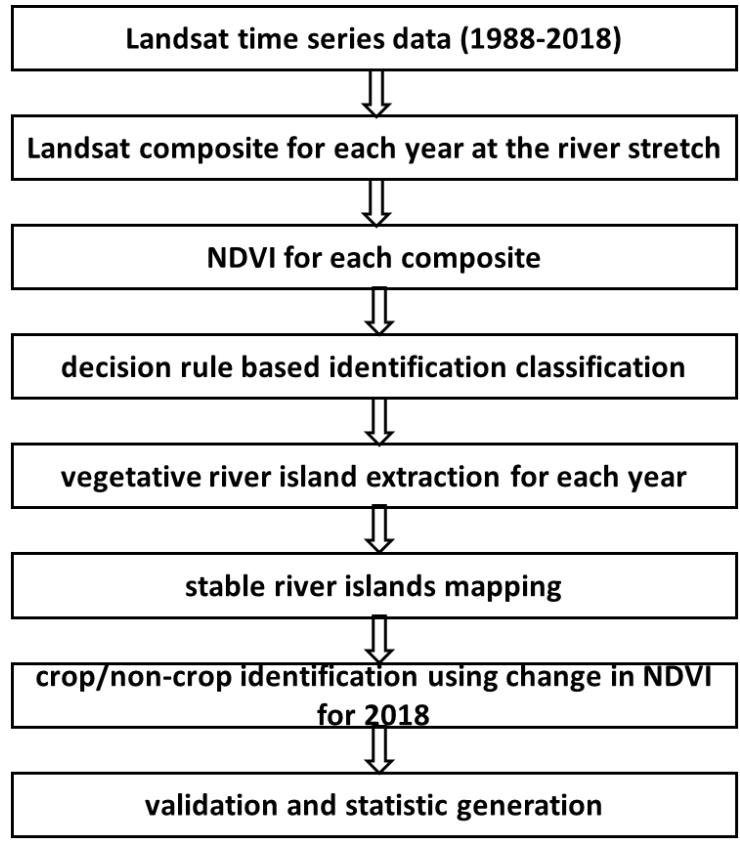

platform. Later the results are exported in GIS platform for generating the statistics. The flowchart of the methodology adopted is shown in figure 2. Temporal vegetative island maps were integrated in GIS environment for detecting of stability/instability and quantification of stable portions of chars over the stipulated 30-year period from 1988 to 2018. Area and the count of the stable chars were also calculated. For calculating the statistics of area and count, the chars were categorized into islands of less than 1 hectare, 1-10 hectares, 10-100 hectares, 100- 500 hectares and above 500 hectares in size.

Figure 2. Methodology flowchart

\section{RESULTS AND DISCUSSIONS}

\subsection{Identification of stable river islands over thirty-year} period

It is observed that total area of vegetative chars has also increased by 52 thousand hectares from 173 thousand hectares in 1988 to 225 thousand hectares in 2018 as shown in figure 3 The chars having area of 500 ha or above has continuously increased in the last three decades whereas chars having area less than 1 ha, 1 ha to 10 ha, 10 ha to 100 ha, 100 ha to 500 ha has either increased or decreased. Total stable char area is approximately 68,180.00 ha. The maximum area (approx. 65 $\%$ ) of these stable chars is occupied by islands having size of more than 500 ha. At present, there are only 17 islands having size greater than 500 hectares which are stable and most of them are in Upper Assam. The total area of stable islands in 2018 was approximately 225 thousand hectare out of which 146 thousand hectare is stable from past 10 years. Among these stable islands of past 10 years, approximately 68 thousand 
hectare are stable since past 30 years i.e. from 1988 onwards. The figure 3 below shows how the river changes its course every decade and the formation and deformation of island with the river course change. The figure 4 below shows the statistics of size wise decadal change of Brahmaputra river islands within the river.
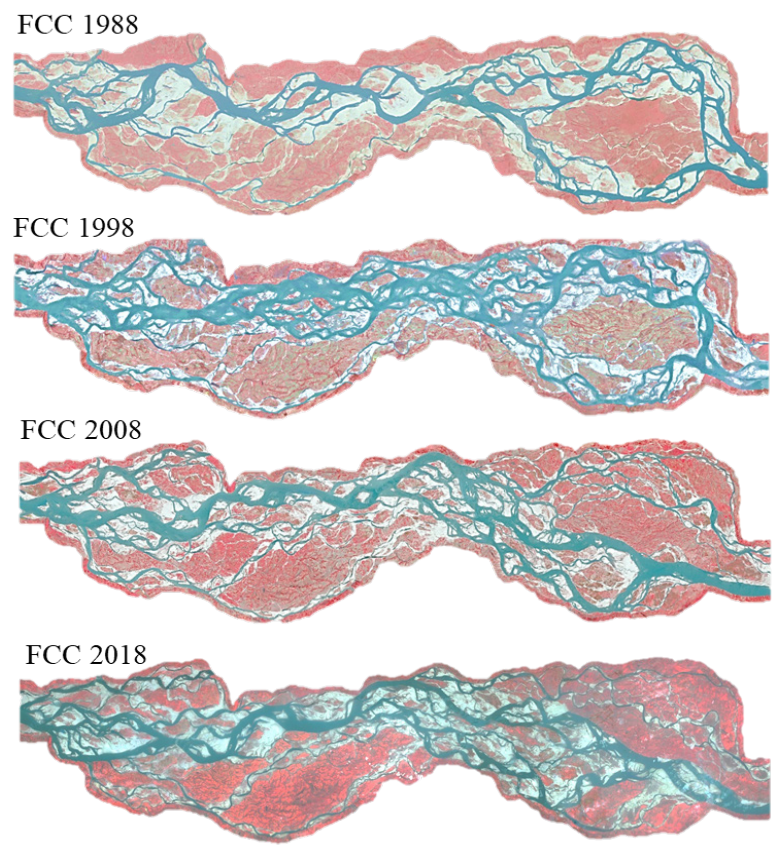

Figure 3. Decadal change of Brahmaputra river and the chars within it

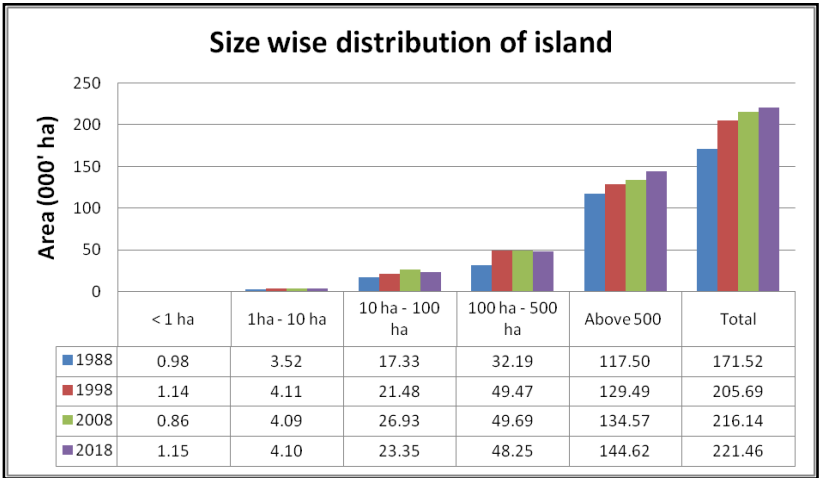

Figure 4. Size wise distribution of Brahmaputra river islands

\subsection{Present status of agriculture pattern in chars}

It is observed that chars having settlement always shows signs of agriculture crops specially in LBV as shown in figure 5 . Thus it can be inferred that people staying in these chars have agriculture as the main source of livelihood. This pattern was validated by analysing the change in NDVI profile throughout the entire stretch of Brahmaputra River. But the vice versa of this pattern was not noted everywhere as many islands which had agriculture land didn't showed signs of settlements. Study reveals that the major crop cultivation is in Lower Brahmaputra Valley (LBV) as shown in figure 6. It was also observed that in many chars, the char dwellers are cultivating not one but two crops during the non-flooding months from November to April.
This was evident from the average NDVI peaks obtained during the non-flooding seasons from the crop fields as shown in Figure 6. In Upper Brahmaputra Valley (UBV), the crop cultivation is almost negligible compared to the size of the islands as shown in figure 7 .

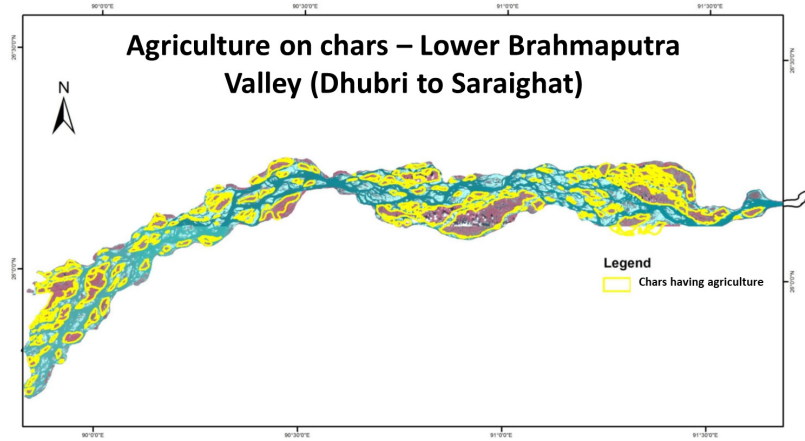

Figure 5. Chars in the Lower Brahmaputra Valley which has agriculture and settlement as seen from Sentinel-2 satellite image

Temporal NDVI images for river islands in LBV
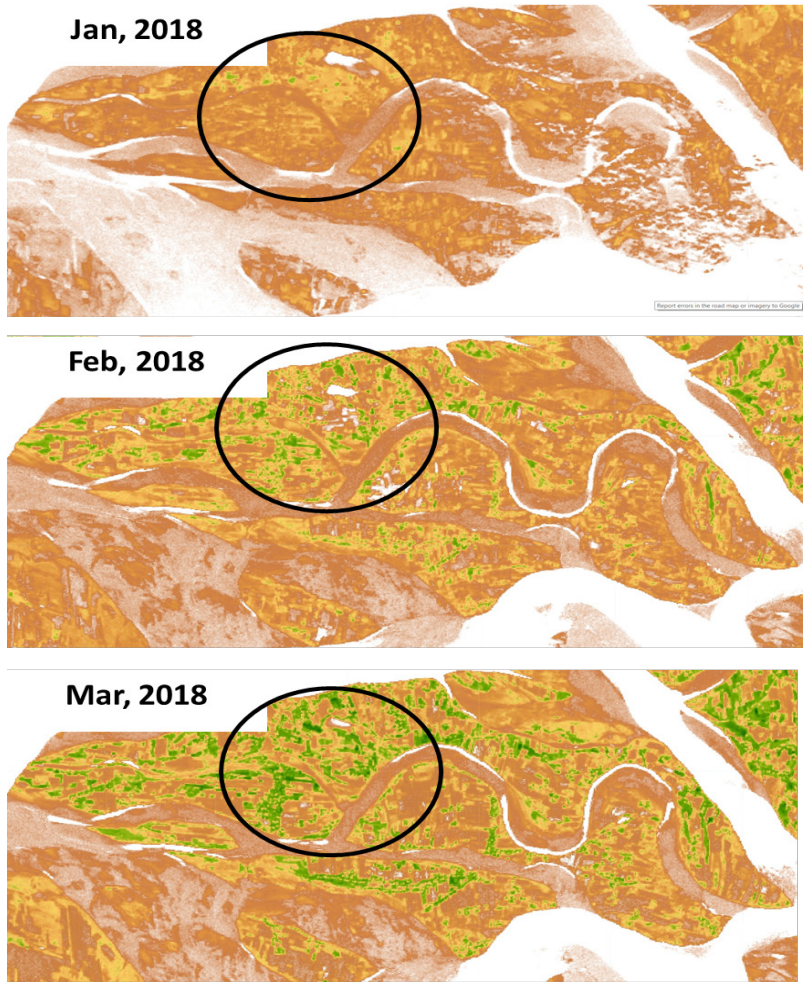

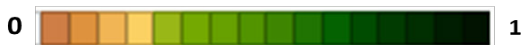

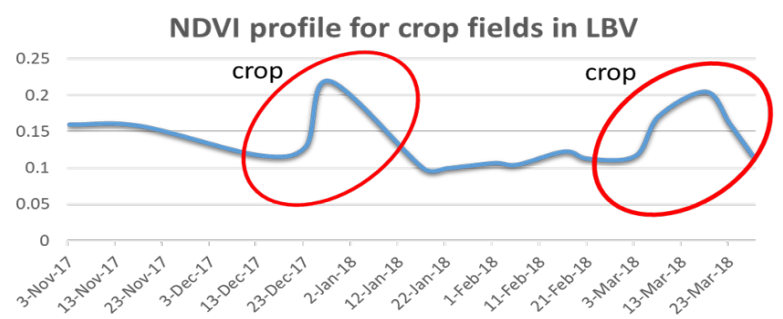

Figure 6. Change in NDVI profile for the non-monsoon season depicting the cropping intensity within the chars in LBV as seen from Sentinel-2 imagery. 
It can be inferred that less stable chars have less agriculture and settlements. The Central Brahmaputra Valley (CBV) shows presence of crops, but there are very less settlements. From this, it can be inferred that though the habitation in the islands of $\mathrm{CBV}$ is less but seasonal migration of the char dwellers is more for crop cultivation in the region. This can also be validated by the fact the CBV region comprise of districts Morigaon, Nagaon, Darrang etc. which has high productivity of vegetables and short duration seasonal crops in the state (https://des.assam.gov.in).

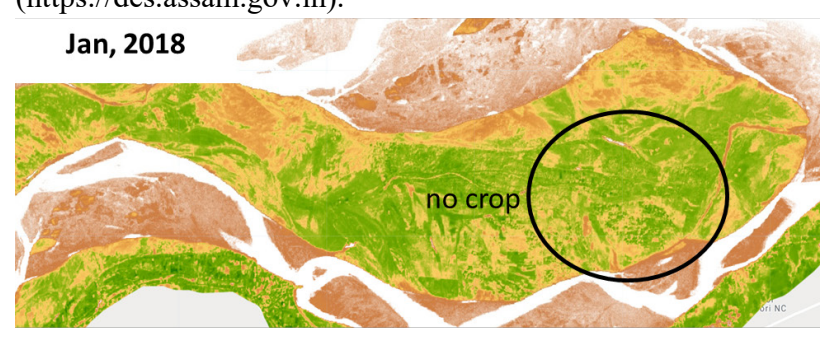

Feb, 2018
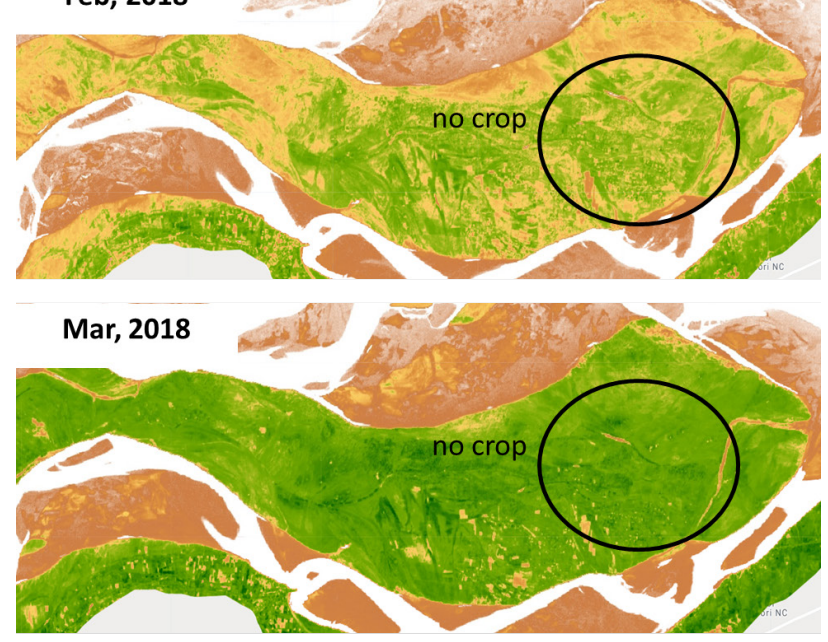

0 \begin{tabular}{l|l|l|l|l|l|l|l|}
\hline$\square$ & 1 & & & & \\
\hline
\end{tabular}

NDVI profile of vegetated area in UBV

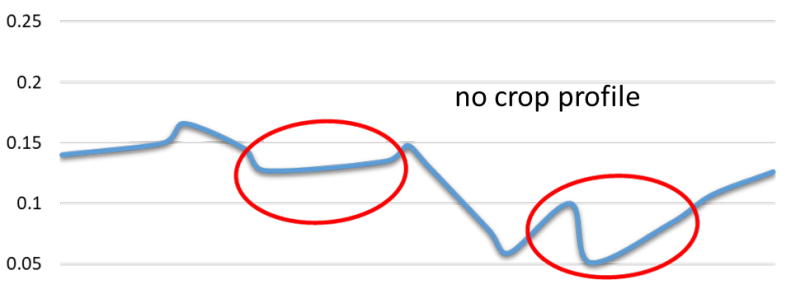

0

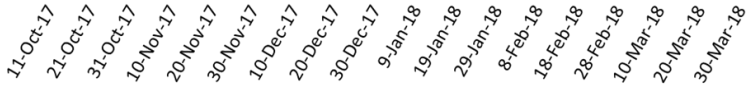

Figure 7. Change in NDVI profile showing fallow land/ no crop within the chars in UBV as seen from Sentinel-2 imagery.

\section{CONCLUSION}

This study shows that island area is increasing continuously, in past thirty years and island area has increased approximately by
50 thousand hectares. The Brahmaputra River has thousands of hectares of unutilized or underutilized alluvial soil especially in UBV and CBV. Soil characteristics, climatic and socioeconomic factors etc. are required to be studied for site suitability analysis for agriculture and horticulture crop expansion. This finding will help the decision makers to better understand the problems of Brahmaputra river bank dynamics and help in proper utilization of river islands for agriculture applications. The local people have no idea about stability /instability of these chars, local people generally grow the seasonal crops without planning. This study can help local peoples to plant the crops according to the change in Brahmaputra river water and to the agriculture department to monitor those agriculture fields. In this way, this study can help in strengthening food security in the region.

\section{ACKNOWLEDGEMENT}

This work was made possible by the guidance and constant support provided by Director and the Scientists of North Eastern Space Applications Center, Department of Space, Meghalaya. The previous work titled "River Course Behavioural study of Brahmaputra using Multi-date satellite data and GIS- Stability of river islands" done by the Water resource team at NESAC was the main guiding source for this work.

\section{REFERENCES}

De UK, Bodosa K (2014) Crop Diversification in Assam and Use of Modern Inputs under Changing Climatic Condition. $\mathrm{J}$ Climatol Weather Forecasting 2: 120. doi:10.4172/23322594.1000120

Gogoi, M., Bordoloi, R. K., 2011. Potential and prospects of Rabi crops cultivation in Assam. Agro-Economic Research Centre for North-East India Assam Agricultural University Jorhat. Study No. 137.

Raising Agricultural Productivity and Making Farming Remunerative for Farmers, 2015. An Occasional Paper by NITI Aayog, Government of India.

Sarkar, A., Garg, R. D., Sharma, Nayan., 2012. RS-GIS Based Assessment of River Dynamics of Brahmaputra River in India. Journal of Water Resource and Protection, 4, pp. 63-72.

Thakuriah, G., and Saikia, R., 2018. RS and GIS based assessment of Bank Erosion in Goalpara District part of Brahmaputra River, Assam, India, International Research Journal of Earth Sciences, ISSN 2321 - 2527, Vol. 6(3), pp. 18.

Lahiri, S.K., Sinha, R., 2012. Tectonic controls on the morphodynamics of the Brahmaputra River system in the upper Assam valley, India, Geomorphology, doi:10.1016/j.geomorph.2012.04.012

River Course Behavioural study of Brahmaputra using Multidate satellite data and GIS- Stability of river islands, 2003. North Eastern Space Applications Centre. Report No. NESACSR-25-2003.

Best, J, L., Ashworth, P, J., Sarker, M, H., and Roden, Julie, E., The Brahmaputra-Jamuna River, Bangladesh, 2007, In book: 
Large Rivers: Geomorphology and Management DOI: 10.1002/9780470723722.ch19

Lahiri-Dutt, K., 2014. Chars-Islands that float within rivers. Shima: The International Journal of Research into Island Cultures Volume 8 Number 2.

Hazarika, N., Das. A.K., Borah S.B., 2015. Assessing land-use changes driven by river dynamics in chronically flood affected upper Brahmaputra plains, India, using RS-GIS techniques. The Egyptian Journal of Remote Sensing and Space Sciences, 18, pp. 107-118.

Rahman, M.A., Rahman, M.M., Char formation process and livelihood characteristics of char dwellers of alluvial river in Bangladesh. ICSE-6, Paris - August pp. 27-31, 2012.

Gorelick, N.; Hancher, M., Dixon, M., Ilyushchenko, S., Thau, D., Moore, R., 2017. Google Earth Engine: Planetary-scale geospatial analysis for everyone. Remote Sens. Environ., 202, pp. $18-27$

Agricultural Statistics in Assam accessed through https:// des.assam.gov.in 